Article

\title{
CAPE Analogs Induce Growth Arrest and Apoptosis in Breast Cancer Cells
}

\author{
Annie-Pier Beauregard ${ }^{1,2, \dagger}$, Jason Harquail ${ }^{1,2, \dagger}$, Grégoire Lassalle-Claux ${ }^{1}$, Mehdi Belbraouet ${ }^{1}$, \\ Jacques Jean-Francois ${ }^{1}$, Mohamed Touaibia ${ }^{1}$ and Gilles A. Robichaud ${ }^{1,2, *}$
}

1 Department of Chemistry and Biochemistry, Université de Moncton, Moncton, NB E1A 3E9, Canada; E-Mail: eab7744@UMoncton.ca (A.-P.B.); ejh8189@umoncton.ca (J.H.); lassalleclaux.gregoire@gmail.com (G.L.-C.); mehdi.b1994@gmail.com (M.B.); jacques.jean-francois@umoncton.ca (J.J.-F.); mohamed.touaibia@umoncton.ca (M.T.)

2 Atlantic Cancer Research Institute, Moncton, NB E1C 8X3, Canada

$\dagger$ These authors contributed equally to this work.

* Author to whom correspondence should be addressed; E-Mail: gilles.robichaud@umoncton.ca; Tel.: +1-506-858-4320; Fax: +1-506-858-4541.

Academic Editors: Jean Jacques Vanden Eynde and Annie Mayence

Received: 28 May 2015 / Accepted: 7 July 2015 / Published: 10 July 2015

\begin{abstract}
Breast cancer is the second leading cause of death amongst women worldwide. As a result, many have turned their attention to new alternative approaches to treat this disease. Caffeic acid phenylethyl ester (CAPE), a well-known active compound from bee propolis, has been previously identified as a strong antioxidant, anti-inflammatory, antiviral and anticancer molecule. In fact, CAPE is well documented as inducing cell death by inhibiting $\mathrm{NF \kappa B}$ and by inducing pro-apoptotic pathways (i.e., p53). With the objective of developing stronger anticancer compounds, we studied 18 recently described CAPE derivatives for their ability to induce apoptosis in breast cancer cell lines. Five of the said compounds, including CAPE, were selected and subsequently characterised for their anticancer mechanism of action. We validated that CAPE is a potent inducer of caspase-dependent apoptosis. Interestingly, some newly synthesized CAPE derivatives also showed greater cell death activity than the lead CAPE structure. Similarly to CAPE, analog compounds elicited p53 activation. Interestingly, one compound in particular, analog 10, induced apoptosis in a p53-mutated cell line. These results suggest that our new CAPE analog compounds may display the capacity to induce breast cancer apoptosis in a p53-dependent and/or independent manner. These
\end{abstract}


CAPE analogs could thus provide new therapeutic approaches for patients with varying genotypic signatures (such as p53 mutations) in a more specific and targeted fashion.

Keywords: breast cancer; CAPE; apoptosis; NFкB; p53; caspase

\section{Introduction}

Breast cancer is still one of the deadliest cancers among women worldwide. Mechanistically, multiple genetic alterations foster the development and progression of cancer cells. For example, the activation of oncogenes and the alteration of tumor suppressor gene pathways are conducive to the development of neoplastic tissues. Essentially, cancer cells lose complete control over highly-regulated cell growth signals, which results in aberrant proliferation while evading programmed cell death or apoptosis [1].

A pivotal regulator of cell growth and survival is the NFKB transcription factor. The deregulation of $\mathrm{NF} \kappa \mathrm{B}$ is considered the cancer cell's green light for proliferation and hyperactivity due to its anti-apoptotic

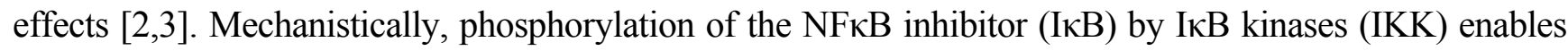
$\mathrm{NF} \kappa \mathrm{B}$ nuclear translocation and induction of pro-survival gene expression [4,5]. Another prominent cancer cell regulator working in concert with $\mathrm{NF \kappa B}$ is the tumor suppressor gene p53. Studies have shown that the pro-apoptotic p53 gene is in fact inactivated or mutated in approximately $64 \%$ of all human cancers (reviewed in [6]). When irreparable genome damage occurs, p53 leads to the induction of the mitochondrial-mediated apoptotic pathway through the activation of pro-apoptotic genes such as Bax and p21 [7-9]. The importance of NFkB and p53 in cell homeostasis is reflected by the ongoing research interests and studies of NFKB and p53 as anticancer strategies [10-12].

The alarming incidence of cancer-related mortality has consistently pushed research toward the identification and development of new effective anticancer therapeutic strategies. A promising source for anticancer drug discovery is the use of bioactive compounds from natural products (reviewed in $[13,14]$ ). Phytochemicals such as polyphenols, flavonoids and phenolic acids have garnered wide interest by the scientific community due to their specific interactions with biological targets $[15,16]$. More specifically, caffeic acid phenylethyl ester (CAPE) (1, Figure 1), a prominent plant phenolic acid, has generated significant attention because of its ability to elicit cancer cell death mainly through the suppression of the cell's survival pathway (i.e., NFкB) [17-19] or concomitant induction of apoptosis cascades (i.e., Bax, p53, etc.) [18,20-22]. Here we present the design of novel CAPE analogs and their capacity to modulated pivotal cell fate signaling cascades resulting in the apoptosis of breast cancer cell models.

\section{Results and Discussion}

\subsection{Biological Evaluation of CAPE Analogs on Breast Cancer Cells}

To establish the biological significance of our novel CAPE derivatives on cancer cell viability, we tested growth inhibition following treatment of CAPE (1) derivatives on the MCF7 non-aggressive breast cancer cell line. The cells were treated with $10 \mu \mathrm{M}$ of the compounds and monitored for cellular viability at 1, 3 and 5 days post-treatment (Figure 2A). As expected, CAPE (1) showed strong growth inhibition 
within $48 \mathrm{~h}$ of treatment and suppressed up to $88 \%$ of growth when compared to the DMSO solvent control samples. Interestingly, many of the CAPE derivatives also showed a similar, if not more effective capacity to inhibit MCF7 growth when compared to the DMSO control cells. A growth inhibition benchmark of $88 \%$ set by the CAPE lead structure was also attained by esters 4, 7, 9, 10, 12, 13 and 17 .

Given that CAPE is well-documented as an efficient inducer of apoptosis, we explored whether the observed growth suppression mediated by our CAPE derivatives was a result of caspase-dependent apoptosis. We thus treated the MCF7 breast cancer cell line with $10 \mu \mathrm{M}$ of our CAPE derivatives and monitored caspase 3/7 activity at 1,3 and 5 days post-treatment (Figure 2B). As expected, CAPE revealed a good capacity to induce apoptosis through a progressive induction of caspase 3/7 activity over the period of 5 days of treatment. Interestingly, we observed that many CAPE derivatives also induced strong apoptotic events when compared to vehicle solvent-treated control cells. In the interest of characterizing new, effective CAPE-derived compounds as anticancer agents, we selected the top five compounds capable of inducing breast cancer apoptosis (i.e., 4, 10, 12, 13, and 17) for further biological elucidation. Accordingly, most of the latter compounds demonstrate greater apoptosis-inducing ability in comparison to CAPE, especially at $48 \mathrm{~h}$ post-treatment.<smiles>[R][X]C(=O)/C=C/c1ccc(O)c(O)c1</smiles>

$\mathrm{CAPE}(1): \mathrm{X}=\mathrm{O} ; \mathrm{R}=\mathrm{CH}_{2} \mathrm{CH}_{2} \mathrm{Ph}$ 19: $\mathrm{X}=\mathrm{NH} ; \mathrm{R}=\mathrm{CH}_{2} \mathrm{CH}_{2} \mathrm{Ph}$<smiles>[R]OC(=O)/C=C/c1ccc(O)c(O)c1</smiles>

$$
\begin{aligned}
& \text { 10: } \mathrm{R}=\mathrm{Ph} \\
& \text { 11: } \mathrm{R}=\mathrm{CH}_{2} \mathrm{Ph} \\
& \text { 12: } \mathrm{R}=\mathrm{CH}_{2} \mathrm{CH}_{2} \mathrm{CH}_{2} \mathrm{Ph} \\
& \text { 13: } \mathrm{R}=\mathrm{CH}_{2} \mathrm{CH}_{2} \mathrm{PhF}(4-\mathrm{F}) \\
& \text { 14: } \mathrm{R}=\mathrm{CH}_{2} \mathrm{CH}_{2} \mathrm{PhMe}(4-\mathrm{Me}) \\
& \text { 15: } \mathrm{R}=\mathrm{CH}_{2} \mathrm{CH}_{2} \mathrm{PhOMe}(4-\mathrm{OMe}) \\
& \text { 16: } \mathrm{R}=\mathrm{CH}_{2} \mathrm{CH}_{2} \mathrm{Ph}\left(4-\mathrm{NO}_{2}\right) \\
& \text { 17: } \left.\mathrm{R}=\mathrm{CH}_{2} \mathrm{CH}_{(\mathrm{Ph}}\right)_{2} \\
& \text { 18: } \mathrm{R}=\mathrm{CH}_{2} \mathrm{CH}_{2} \mathrm{Naph}
\end{aligned}
$$

Figure 1. Caffeic Acid Phenethyl Ester (CAPE) derivatives.

Cellular viability (MCF7)

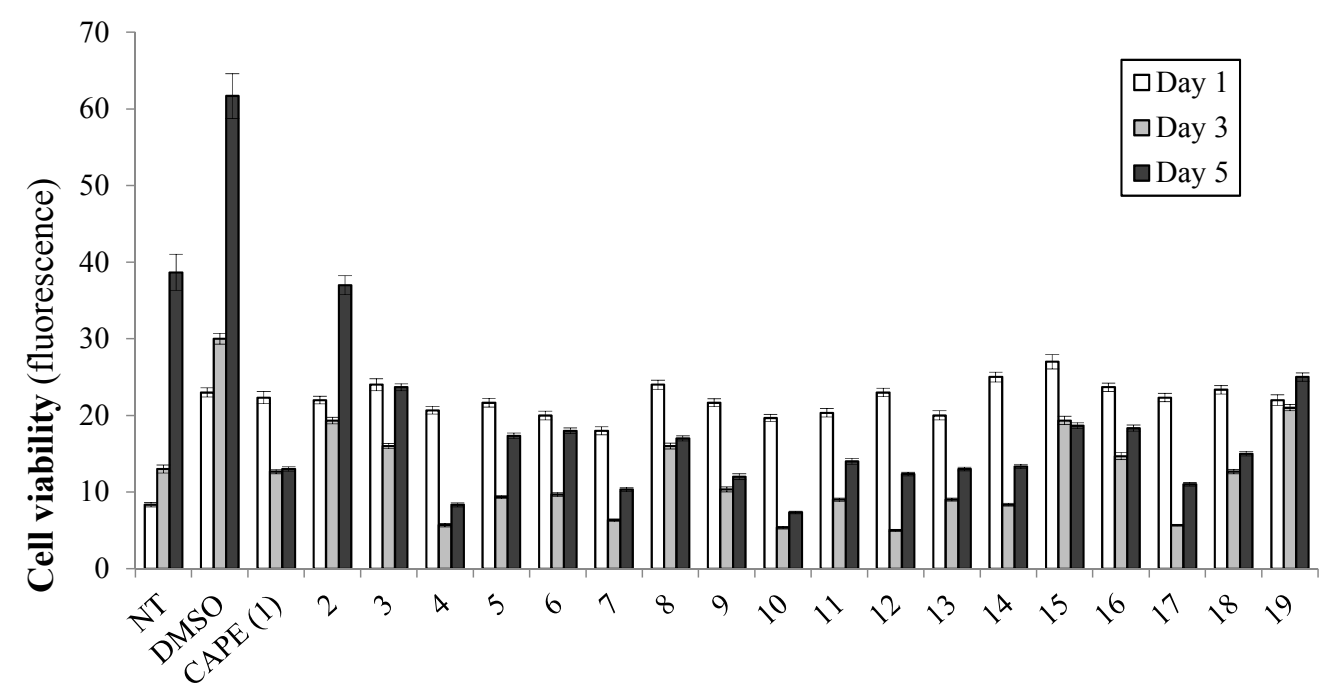

(A)

Figure 2. Cont. 


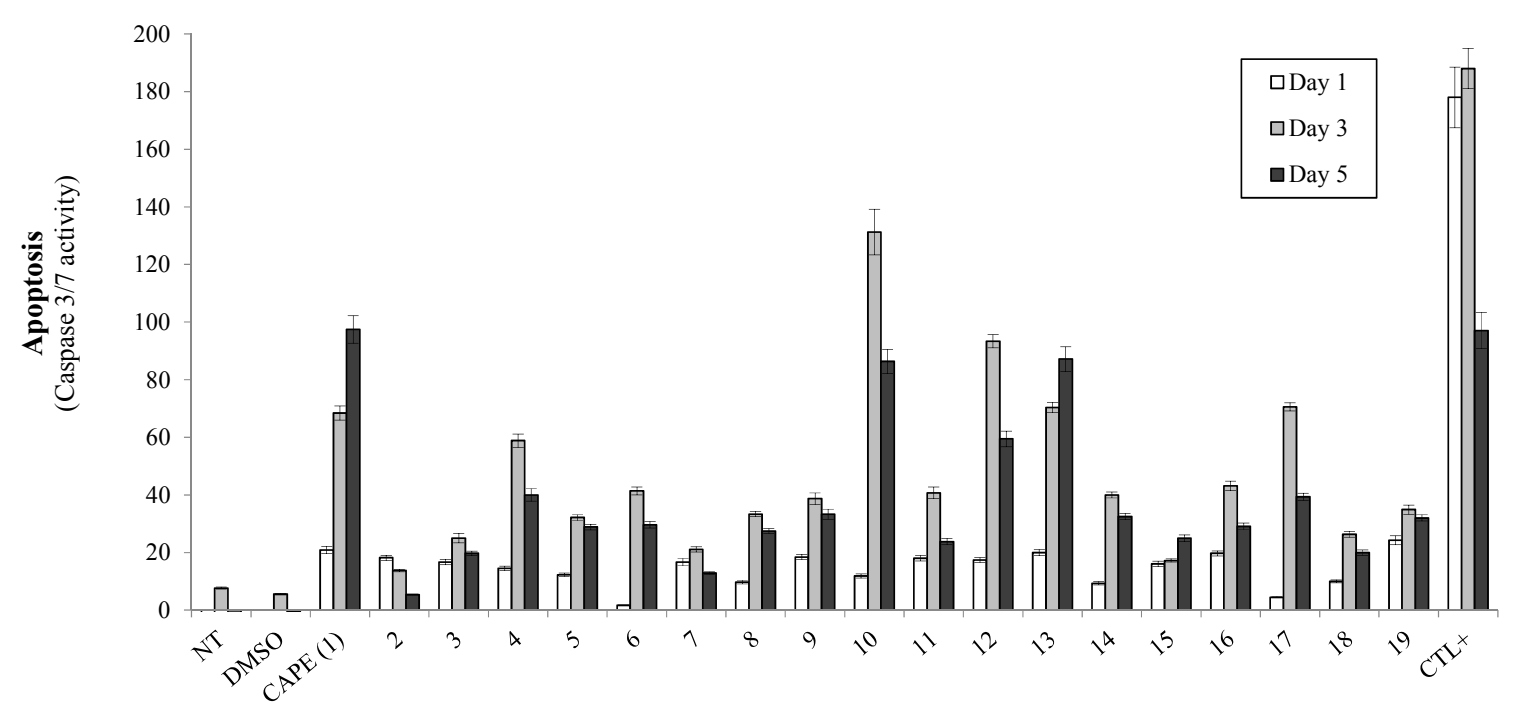

(B)

Figure 2. Biological effects of CAPE derivatives on breast cancer cells. MCF7 breast cancer cells were treated with $10 \mu \mathrm{M}$ of selected compounds and incubated in time (24, 72 and $120 \mathrm{~h}$ ) and evaluated for (A) cell viability assay (Cell-Titer Blue, Promega) or (B) caspase-dependent apoptotic events (Apo-ONE, Promega). Control samples include non-treated (NT) and solvent (DMSO) treated cells in addition to cells treated with apoptosis-inducing agent Melphalan $(5 \mu \mathrm{M})$ as a positive control $(\mathrm{CTL}+)$. Results and standard deviations are representative of biological and experimental triplicates where the data is presented as the means $\pm \mathrm{SEM}$.

\subsection{Modulation of Cell Fate Signaling by Selected CAPE Analogs in Breast Cancer Cells}

It has been well-established that CAPE is a potent inhibitor of $\mathrm{NF \kappa B}$, a pivotal regulator of cancer cell growth and survival $[18,19,23,24]$. We thus set out to evaluate the capacity of selected CAPE derivatives

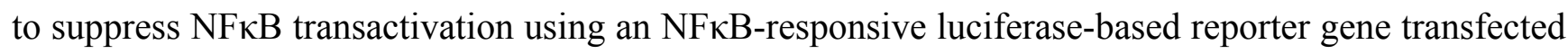
into the MCF7 breast cancer cell line. Interestingly, none of the CAPE analogs tested (4, 10, 12, 13 and 17) demonstrated any significant differences in their respective capacity to modulate NFKB-luciferase activity when compared to the CAPE lead compound (Figure 3A). The use of an IKK inhibitor (IKK-2 Inhibitor IV/10 $\mu \mathrm{M}$ ) as a positive control however, inhibited NFkB-luciferase activity up to $53 \%$.

We next wanted to explore the compounds' ability to modulate other cancer cell pathways that could potentially explain their capacity to modulated breast cancer cell viability and apoptosis. Given that CAPE has previously been shown to activate the p53 pathway $[18,22]$, we evaluated whether selected CAPE derivatives could induce $\mathrm{p} 53$ transactivation using a p53-responsive p21-luciferase reporter construct transfected into MCF7 cells. Interestingly, all selected CAPE analogs $(4,10,12,13$ and 17) induced greater p53 transactivation in MCF7 cells when compared to CAPE treatment alone (Figure 3B). More notably, esters 4 and 12, with a propyl or phenylpropyl group, induced a $\sim 1.75$ - and $\sim 1.5$-fold increase, respectively, over CAPE treatments. 
NFкB Reporter Activity (MCF7)

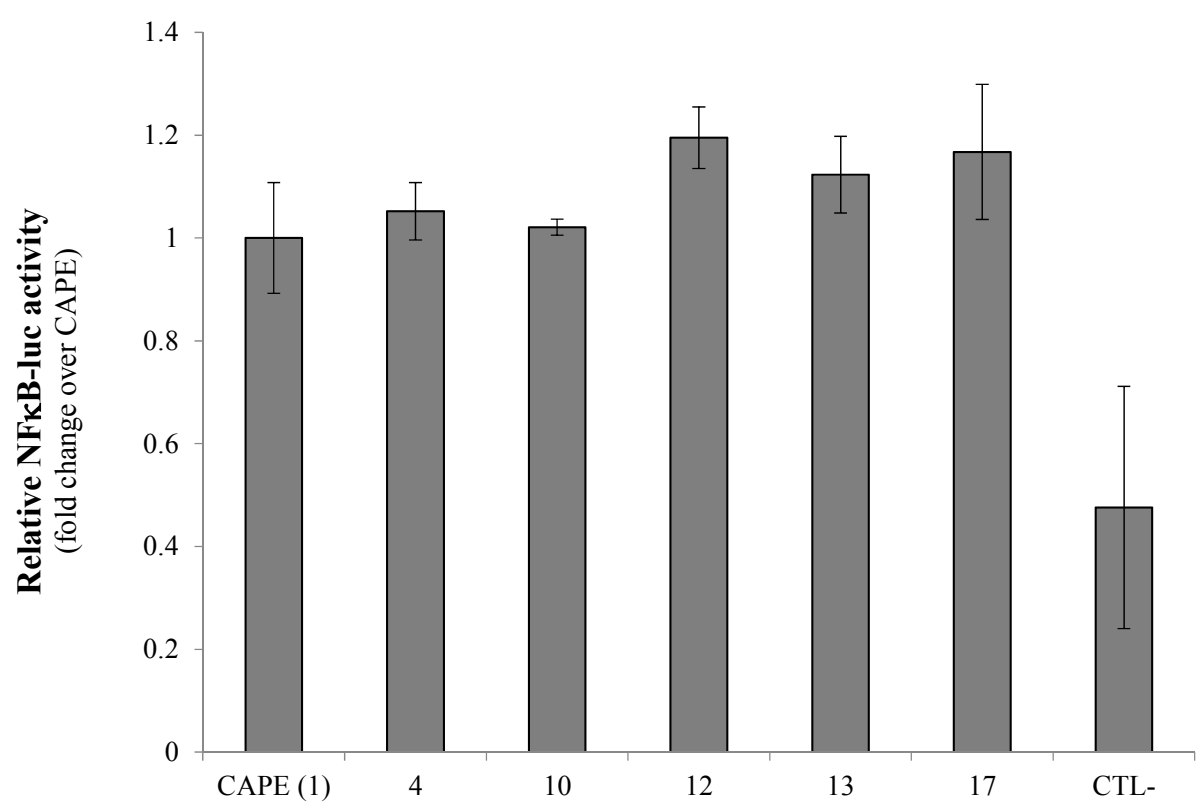

(A)

p21 Reporter Activity (MCF7)

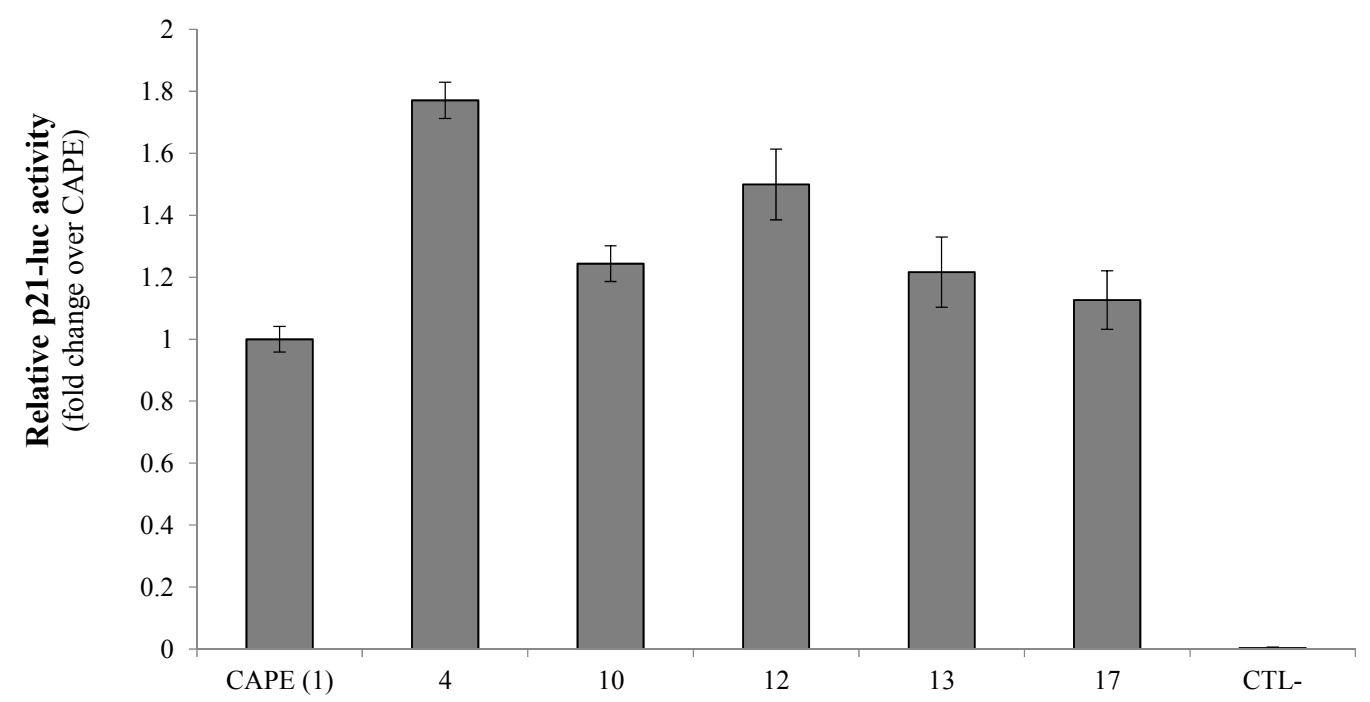

(B)

Figure 3. Modulation of cell fate regulators by selected CAPE analogs in breast cancer cells. MCF7 breast cancer cells were treated with $10 \mu \mathrm{M}$ of selected compounds and evaluated for (A) NFkB and (B) p53 transactivation potential using NFkB-luciferase and p53-responsive p21-luciferase reporter gene constructs respectively. Relative light units (RLU) from normalized luciferase activity were then plotted in fold-change activity over the parent core CAPE compound. Control samples include the treatment with an IKK inhibitor (IKK-2 Inhibitor IV/10 $\mu \mathrm{M}$ ) used as a positive control. Data is represented as means \pm SEM of three experimental replicates. 


\subsection{Evaluation of p53-Mediated Apoptosis by CAPE Analogs in Breast Cancer Cells}

Given that the selected CAPE analogs $(4,10,12,13$ and 17) elicit greater p53 transactivation than the CAPE parental compound, we set out to determine whether the latter gain of p53 activity accounts for greater apoptosis potential in breast cancer cells. We thus made use of the MB231 aggressive breast cancer cell line, which lacks a functional p53 due to mutation. MB231 cells were treated with $10 \mu \mathrm{M}$ of selected CAPE analogs and monitored over time (days 1, 3 and 5) for caspase-dependent apoptosis (Figure 4). Interestingly, all CAPE analogs, with the exception of CAPE itself and 10, lost their ability to induce apoptosis in MB231 cells. These results suggest that CAPE and $\mathbf{1 0}$ compounds may mediate apoptosis predominantly through a p53-independent pathway.

\section{Caspase-dependent apoptosis (MB231)}

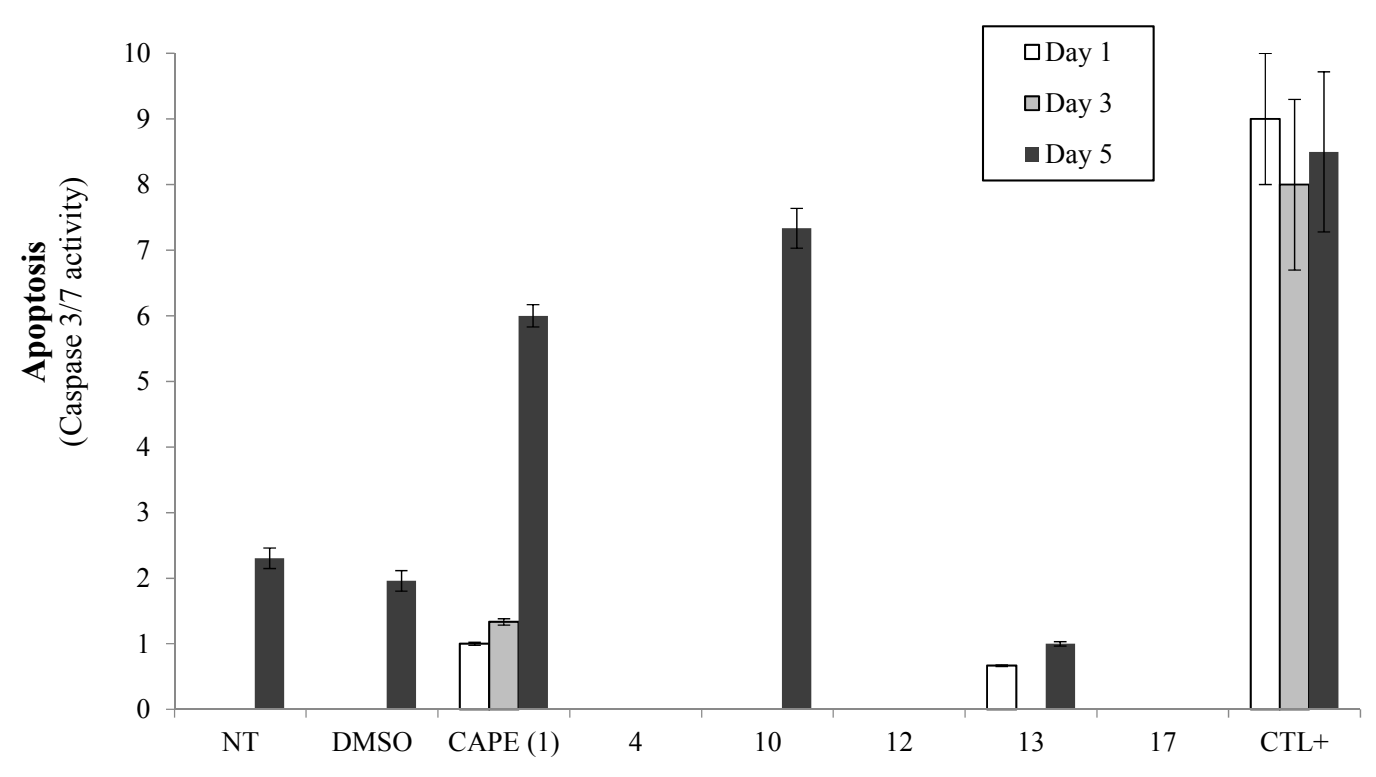

Figure 4. p53-Dependent apoptosis by CAPE derivatives in breast cancer cells. MB231 breast cancer cells were treated with $10 \mu \mathrm{M}$ of selected compounds and incubated over time (24, 72 or $120 \mathrm{~h}$ ) and evaluated for caspase-dependent apoptosis (Apo-ONE, Promega). Control samples include non-treated (NT) and solvent (DMSO) treated cells in addition to cells treated with apoptosis-inducing agent Melphalan $(5 \mu \mathrm{M})$ as a positive control (CTL+). Results and standard deviations are representative of biological and experimental triplicates where the data is presented as the means \pm SEM.

\subsection{Antioxidative Potential of CAPE Analogs in Breast Cancer Cells}

It has been shown that apoptosis can also be induced by the alteration of the cell's redox potential $[25,26]$. We therefore explored the capacity of the selected CAPE derivatives to elicit antioxidant activity as free radical scavengers. As depicted in Table 1, we observed that compounds $\mathbf{1 7}$ and CAPE displayed the highest antioxidant activity with $\mathrm{IC}_{50}$ values of 18.5 and $16.5 \mu \mathrm{M}$, respectively. These observations suggest that the redox modulation of CAPE, and more specifically 10, may account for their potency to induce apoptosis through an extrinsic pathway. 
Table 1. Antioxidant activity of selected CAPE derivatives.

\begin{tabular}{cc}
\hline Compounds & IC $_{\mathbf{5 0}} \pm \mathbf{S E M}(\boldsymbol{\mu M})$ \\
\hline $\mathrm{CAPE}^{1}$ & $16.5 \pm 4.0$ \\
4 & $14.2 \pm 1.7$ \\
10 & $12.5 \pm 2.6$ \\
12 & $11.9 \pm 0.6$ \\
13 & $12.8 \pm 1.1$ \\
17 & $18.5 \pm 2.1$ \\
\hline
\end{tabular}

${ }^{1}$ Antioxidant activity as free radical scavengers of CAPE and its derivatives expressed as $\mathrm{IC}_{50}$. Values are means of 2 independent experiments, each performed in triplicate.

\subsection{Discussion}

As with many naturally derived compounds, CAPE has been extensively studied to elucidate its health benefits. Recently, this compound has seen a surge in interest as a potent anticancer drug [17,18,27]. In fact, CAPE has already been shown to inhibit breast cancer growth, while preserving the integrity of non-tumorigenic mammary epithelia cells [17]. However, in the interest of developing more efficient and targeted cancer treatments, it is crucial to explore new chemically derived compounds which could ultimately produce analogs with higher anti-cancer activity. More specifically, pharmacological properties with apoptosis-inducing capabilities are highly sought after, as they provide an effective, non-inflammatory approach to eliminating cancer cells to regain tissue homeostasis [28].

In this study, we explore the anticancer properties of 19 compounds, including the naturally derived CAPE as well as 18 novel synthetic analogs - 17 esters (2-18) and one amide (19). We observe that CAPE derivatives effectively suppress breast cancer cell viability, with some of the esters showing greater inhibition of MCF7 breast cancer cell growth than CAPE itself and its amide analog (19). Given that apoptosis malfunction is a key hallmark of cancer development and tumor-cell survival, we evaluated the capacity of our panel of CAPE analogs for caspase 3/7 apoptosis activity in MCF-7 cells and observed that many derivatives (i.e., 1, 4, 10, 12, 13 and 17) induce strong caspase-dependent apoptosis events either equal to, or greater than, the lead reference compound. These findings are in agreement with previous reports demonstrating the potency of CAPE as an inducer of apoptosis [18,29-32]. Although we do not have a general trend, the replacement of the phenethyl moiety of CAPE with a propyl (4) or a phenyl (10) seems to be favorable for triggering apoptosis in MCF7 cells compared to CAPE lead structure. Moreover, the presence of a fluorine (13) or the replacement of the phenyl of CAPE by a biphenyl (17) or by a benzyl (12) appear to be favorable for apoptosis.

In our attempt to elucidate the mechanisms of action for CAPE analog-mediated apoptosis in breast cancer cells, we selected the top five apoptosis-inducing compounds for further biological characterisation. First, we wanted to assess the capacity of novel CAPE analogs to modulate cell survival pathways

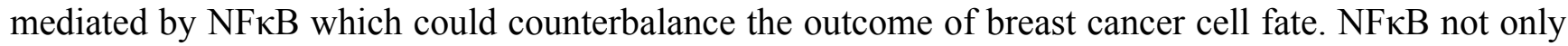
promotes neoplastic transformation but also activates anti-apoptotic proteins and signaling (reviewed in $[2,5])$. However, we did not see any significant changes in their respective capacity to modulate NFkB activation when compared to CAPE alone. These observations strongly suggest that: (1) the core structure of the lead CAPE compound is likely responsible for CAPE's reported ability to suppress 
$\mathrm{NF \kappa B}$ activity [18,33]; and (2) structure modifications did not account for changes of the NFkB survival pathway.

We next explored the capacity of the compounds to activate the p53 pathway, which has been previously demonstrated by CAPE [18,34]. P53-mediated signaling commonly induces caspase-dependent apoptosis, proving to be a potent target during cancer-associated pathway deregulation [6]. Mechanistically, cancer cells profit from these molecular cascades to promote tumor growth and aggressivity. Interestingly, all selected CAPE analogs tested demonstrated greater potential to induce p53 transactivation when compared to CAPE. We observed that the replacement of CAPE's phenethyl moiety by either a propyl (4) or a phenyl (10) induces p53 tumor suppressor activity which would likely lead to cancer cell apoptosis sensitivity. In addition, the presence of a fluorine (13) or, the replacement of CAPE's phenyl by either a biphenyl (17) or a benzyl (12) also results in p53 induction which would be favorable for triggering apoptosis. We next wanted to define whether the gain of p53 activity accounts for the compounds' apoptotic inducing ability using the MB231 p53-mutated breast cancer cell line [35]. Surprisingly, all tested compounds lost their ability to induce apoptosis with the exception of CAPE and 10, thus suggesting that 4, 12, 13 and 17 may induce apoptosis in a p53 dependent manner. On the other hand, CAPE and $\mathbf{1 0}$ may alternatively make use of the extrinsic apoptosis pathway. These observations correlate with studies conducted by Nomura et al. (2001) which demonstrate the ability of CAPE to induce carcinoma cell apoptosis in both a p53-dependent and independent manner [22]. This being said, the structural modifications or similarities between CAPE, $\mathbf{1 0}$ and the other derivatives may define apoptotic signaling through either a p53-dependent or independent cascade. Compared to CAPE, 4, 10, 13 and 17, as a phenyl ester, 10 is the least flexible of the series. These findings are of particular relevance when considering that inactivation or mutation of the p53 tumor suppressor gene is the most common alteration found in human cancers (up to 64\%) (reviewed in [6]). Lead compound modifications such as $\mathbf{1 0}$ in this case could represent an effective anti-tumor strategy in cancers bearing p53 mutations.

Recently, research in $\mathrm{p} 53$-independent apoptosis has garnered interest to ultimately provide new therapeutic opportunities for many cancers [36]. p53-independent apoptosis, or the extrinsic apoptotic pathway, is usually induced by the binding of ligands to their cognate death receptors from the tumor necrosis factor receptor (TNFR) gene superfamily such as Fas/Fas ligand, TNF/TNF receptor [37-39], or less traditional death ligand/receptor interactions such as Apo2L/DR4, Apo2L/DR5 or Apo3L/DR3 [40-43]. These interactions eventually lead to the activation of effector caspases (caspases-3, -6 and -7) resulting in DNA fragmentation. NFKB activation also regulates cell death via the regulation of TNFR extrinsic factors which result in p53-independent cell apoptosis [44,45]. Accordingly, CAPE has previously been shown to induce extrinsic apoptosis through Apo2L/DR4 and DR5 receptors as well as Fas/Fas ligand interactions $[18,46,47]$.

Another possibility is that $\mathbf{1 0}$ could mediate apoptosis through oxidative stress and the production of reactive oxygen species (ROS). ROS is a collective term that broadly describes $\mathrm{O}_{2}$-derived free radicals that can induce extrinsic apoptosis through the activation of JNK or attack DNA directly (reviewed in $[25,26])$. We and others have demonstrated the potential of CAPE structures to modulate the cell's redox state [48-50]. We also observe that $\mathbf{1 0}$ is among the weakest antioxidants in our panel of analogs, suggesting a pro-oxidative potential that sensitizes cancer cells to extrinsic apoptotic events. A study by Choi and colleagues (2007) brings support to this latter hypothesis by demonstrating that CAPE sensitizes astrocytoma cells to Fas-induced apoptosis in a redox-dependent manner [51]. Alternatively, 
extrinsic apoptotic mechanisms could be at play to elucidate the potency of CAPE and $\mathbf{1 0}$ treatments in the induction of breast cancer cell apoptosis. The paucity of information in regards to the specific mechanism of action associated to CAPE analogs such as $\mathbf{1 0}$ in p53-independent apoptosis warrants further investigation as a potential anticancer drug.

\section{Experimental Section}

\subsection{CAPE Analog Synthesis}

As recently reported [52], alkyl 2-9 and aryl esters 10-18 were synthesized by esterification with selected alcohol and caffeic acid or acetylated caffeic acid. Amide 19 was synthesized from 2-phenylethanamine and acetylated caffeic acid. De- $O$-acetylation of the precursors of 10-18 and 19 resulted in the desired caffeic acid derivatives (Figure 1). The substituents were selected for their electronic and steric properties. To explore the effects of flexibility, addition of an insaturation (8) as well as the modification of the alkyl linker length $(\mathbf{1 0}, \mathbf{1 1}, \mathbf{1 2})$ were investigated. The effects of additional phenyl moiety $(\mathbf{1 7}, \mathbf{1 8})$ as well as electron withdrawing and donating $p$-substituents $(\mathbf{1 6}, \mathbf{1 7})$ were investigated.

\subsection{Cell Culture and Treatments}

MCF7 and MDA-MB-231 (MB231) breast cancer cell lines were obtained from American Type Culture Collection (ATCC, Manassas, VA, USA). The cells were cultured in Dulbecco's Modified Eagle's Medium (DMEM) supplemented with 10\% fetal bovine serum (FBS), 2 mM L-glutamine and $0.01 \mathrm{mg} / \mathrm{mL}$ of recombinant human insulin (MCF7). Cells were maintained in exponential growth and at $37{ }^{\circ} \mathrm{C}$ with $5 \% \mathrm{CO}_{2}$. DMEM was obtained from HyClone (Thermo Scientific, Rockford, IL, USA), FBS from PAA Laboratories (Etobicoke, ON, Canada) and other reagents from Sigma-Aldrich (St. Louis, MO, USA).

Treatments consisted of CAPE derivatives reconstituted in DMSO at the indicated concentrations and incubated for the specified time points with cells seeded in 96-well microplates. In the specified experiments, cells were submitted to chemical inducers of caspase-dependent apoptosis (Melphalan/5 $\mu \mathrm{M}$ ) or inhibitors of NFאB (IKK-2 Inhibitor IV/10 $\mathrm{kM}$ ) used as controls.

\subsection{Cell Viability and Apoptosis Assays}

$5 \times 10^{3}$ cells were seeded in 96-well plates and analyzed at the indicated time points for cellular viability and apoptosis using multiplex assays CellTiter Blue ${ }^{\circledR}$ and Apo-ONE ${ }^{\circledR}$ kits respectively (Promega, Madison, WI, USA) according to the manufacturer's instructions. In brief, $20 \mu \mathrm{L}$ of CellTiter Blue ${ }^{\circledR}$ substrate was added to $100 \mu \mathrm{L}$ of media containing the cells and incubated at $37^{\circ} \mathrm{C}$ for $1 \mathrm{~h}$. Then, the microplates were subjected to analysis on a fluorescence microplate reader (FLUOstar Optima, BMG Lab technologies, $544_{\mathrm{Ex}} / 590_{\mathrm{Em}}$ ). Apoptosis was then measured on the same microplate by removing $80 \mu \mathrm{L}$ of the total media and adding $40 \mu \mathrm{L}$ of the Apo-ONE ${ }^{\circledR}$ substrate. Next, the microplate was incubated at room temperature for $1 \mathrm{~h}$ on a plate shaker and analyzed by fluorescence reading $\left(485_{\mathrm{Ex}} / 520 \mathrm{Em}\right)$. 


\subsection{Cell Transfections and Luciferase-Based Reporter Assay}

Transfections were carried out using the XtremGENE reagent (Roche, Branford, CT, USA) according to the manufacturer's guidelines. Briefly, cells were seeded in six-well plates $24 \mathrm{~h}$ pre-transfection at a density of $3 \times 10^{5}$ cells/well. Cells were then incubated with a DNA-reagent complex (ratio of $2 \mu \mathrm{g}$ of DNA/ $5 \mu \mathrm{L}$ reagent) for $24 \mathrm{~h}$ in OPTI-MEM in reduced serum without antibiotics. Luciferase-based reporter gene assays were conducted using the Dual-Glo luciferase system (Promega) as described previously [53]. Briefly, cells were transfected with $2 \mu \mathrm{g}$ of either a NFkB-luciferase construct [54]; or, a p53-responsive p21 promoter luciferase gene construct [55], lysed and analyzed for luciferase activity using a luminometer (BMG Fluostar, Fisher Scientific, Ottawa, ON, Canada). Relative reporter activity was calculated using experimental triplicates.

\subsection{Radical Scavenging Activity}

To determine the antioxidant activity of CAPE analogs, we measured their ability to reduce free radicals. The radical scavenging activity of CAPE derivatives was measured using a 2,2-diphenyl-1picrylhydrazyl-(DPPH)-based radical generating system as previously described [56]. This assay measures the capacity of compounds to reduce free radicals through an electron transfer (ET) mechanism [57]. Controls within an optical density range of $0.350-0.360$ at $520 \mathrm{~nm}$ were considered acceptable to avoid variations in the calculation of $\mathrm{IC}_{50}$ values. A solution of $60 \mathrm{mM}$ DPPH (1 mL in ethanol) was mixed with $1 \mathrm{~mL}$ (in ethanol) of increasing concentrations of each CAPE derivative or with ethanol alone. Each mixture was then shaken vigorously and kept in the dark for 30 min at room temperature, after which the absorbance of DPPH at $520 \mathrm{~nm}$ was measured.

\section{Conclusions}

Altogether, our findings further validate the efficacy of CAPE as a potent anticancer agent as well as putting forth new CAPE-derivative compounds that show promising anticancer activity. Amongst these esters, we present their respective apoptotic inducing activities in both p53 competent and p53 mutant breast cancer cell lines. We strongly believe that CAPE, as well as possible derivatives including those shown here, warrant further investigation to create the possibility of adapting such analogs into promising therapeutic anticancer regimes.

\section{Acknowledgments}

Financial support for this research was provided by the New Brunswick Innovation Foundation, the New Brunswick Health Research Foundation, Natural Sciences and Engineering Research Council of Canada, the Canadian Breast Cancer Foundation-Atlantic Chapter, the Canadian Breast Cancer Society/QEII Foundation and Université de Moncton. GAR is also supported by a Canadian Institutes of Health Research (CIHR) New Investigator Award. APB is supported by a TD Bank Graduate Student Research Award at the Atlantic Cancer Research Institute. JH is supported by a trainee award from the Beatrice Hunter Cancer Research Institute, with funds provided by the Cancer Research Training Program as part of The Terry Fox Foundation Strategic Health Research Training Program in Cancer Research at CIHR. 


\section{Author Contributions}

APB conducted the biological assays; GLC, MB and MT designed, synthesized and validated all CAPE analogs; JJF conceived and elaborated the radical activity assays; APB, JH and GAR wrote the paper.

\section{Conflicts of Interest}

The authors declare no conflict of interest.

\section{Abbreviations}

CAPE: Caffeic Acid Phenylethyl Ester

NFкB: Nuclear Factor of kappa B Cells

p53: tumor suppressor gene p53

IкB: NFאB inhibitor

IKK: IкB kinases

DMSO: Dimethylsulfoxide

$\boldsymbol{\mu M}$ : micromolar

IC $_{\mathbf{5 0}}$ : Half maximal inhibitory concentration

TNF: tumor necrosis factor

TNFR: tumor necrosis factor receptor

Apo/DR: Trail receptor or Death receptor

ROS: reactive oxygen species

\section{References}

1. Jia, L.T.; Zhang, R.; Shen, L.; Yang, A.G. Regulators of carcinogenesis: Emerging roles beyond their primary functions. Cancer Lett. 2015, 357, 75-82.

2. Baeuerle, P.A.; Henkel, T. Function and activation of NF-kappaB in the immune system. Annu. Rev. Immunol. 1994, 12, 141-179.

3. Siebenlist, U.; Franzoso, G.; Brown, K. Structure, regulation and function of NF-kappaB. Annu. Rev. Cell. Biol. 1994, 10, 405-455.

4. Karin, M.; Ben-Neriah, Y. Phosphorylation meets ubiquitination: The control of NF-[kappa]B activity. Annu. Rev. Immunol. 2000, 18, 621-663.

5. Ghosh, S.; Karin, M. Missing pieces in the NF-kappaB puzzle. Cell 2002, 109 (Suppl. 109), S81-S96.

6. Vogelstein, B.; Lane, D.; Levine, A.J. Surfing the p53 network. Nature 2000, 408, 307-310.

7. Thornborrow, E.C.; Manfredi, J.J. The tumor suppressor protein p53 requires a cofactor to activate transcriptionally the human bax promoter. J. Biol. Chem. 2001, 276, 15598-15608.

8. Toshiyuki, M.; Reed, J.C. Tumor suppressor p53 is a direct transcriptional activator of the human bax gene. Cell 1995, 80, 293-299.

9. Kastan, M.B.; Onyekwere, O.; Sidransky, D.; Vogelstein, B.; Craig, R.W. Participation of p53 protein in the cellular response to DNA damage. Cancer Res. 1991, 51, 6304-6311. 
10. Yap, J.L.; Worlikar, S.; MacKerell, A.D., Jr.; Shapiro, P.; Fletcher, S. Small-molecule inhibitors of the erk signaling pathway: Towards novel anticancer therapeutics. ChemMedChem 2011, 6, 38-48.

11. Kohno, M.; Pouyssegur, J. Targeting the ERK signaling pathway in cancer therapy. Ann. Med. 2006, 38, 200-211.

12. Wang, W.; Hu, Y. Small molecule agents targeting the p53-mdm2 pathway for cancer therapy. Med. Res. Rev. 2012, 32, 1159-1196.

13. Mukhtar, E.; Adhami, V.M.; Khan, N.; Mukhtar, H. Apoptosis and autophagy induction as mechanism of cancer prevention by naturally occurring dietary agents. Curr. Drug Targets 2012, 13, 1831-1841.

14. Beutler, J.A. Natural Products and Cancer Drug Discovery; Springer: New York, NY, USA, 2013; p. 244.

15. Mates, J.M.; Segura, J.A.; Alonso, F.J.; Marquez, J. Natural antioxidants: Therapeutic prospects for cancer and neurological diseases. Mini Rev. Med. Chem. 2009, 9, 1202-1214.

16. Mates, J.M.; Segura, J.A.; Alonso, F.J.; Marquez, J. Anticancer antioxidant regulatory functions of phytochemicals. Curr. Med. Chem. 2011, 18, 2315-2338.

17. Wu, J.; Omene, C.; Karkoszka, J.; Bosland, M.; Eckard, J.; Klein, C.B.; Frenkel, K. Caffeic acid phenethyl ester (cape), derived from a honeybee product propolis, exhibits a diversity of anti-tumor effects in pre-clinical models of human breast cancer. Cancer Lett. 2011, 308, 43-53.

18. Watabe, M.; Hishikawa, K.; Takayanagi, A.; Shimizu, N.; Nakaki, T. Caffeic acid phenethyl ester induces apoptosis by inhibition of nfkappab and activation of fas in human breast cancer MCF-7 cells. J. Biol. Chem. 2004, 279, 6017-6026.

19. Natarajan, K.; Singh, S.; Burke, T.R., Jr.; Grunberger, D.; Aggarwal, B.B. Caffeic acid phenethyl ester is a potent and specific inhibitor of activation of nuclear transcription factor NF-kappa B. Proc. Natl. Acad. Sci. USA 1996, 93, 9090-9095.

20. Chen, Y.J.; Shiao, M.S.; Wang, S.Y. The antioxidant caffeic acid phenethyl ester induces apoptosis associated with selective scavenging of hydrogen peroxide in human leukemic HL-60 cells. Anticancer Drugs 2001, 12, 143-149.

21. Ulasli, S.S.; Celik, S.; Gunay, E.; Ozdemir, M.; Hazman, O.; Ozyurek, A.; Koyuncu, T.; Unlu, M. Anticancer effects of thymoquinone, caffeic acid phenethyl ester and resveratrol on a549 non-small cell lung cancer cells exposed to benzo(a)pyrene. Asian Pac. J. Cancer Prev. 2013, 14, 6159-6164.

22. Nomura, M.; Kaji, A.; Ma, W.; Miyamoto, K.; Dong, Z. Suppression of cell transformation and induction of apoptosis by caffeic acid phenethyl ester. Mol. Carcinog. 2001, 31, 83-89.

23. Onori, P.; DeMorrow, S.; Gaudio, E.; Franchitto, A.; Mancinelli, R.; Venter, J.; Kopriva, S.; Ueno, Y.; Alvaro, D.; Savage, J.; et al. Caffeic acid phenethyl ester decreases cholangiocarcinoma growth by inhibition of NF-kappaB and induction of apoptosis. Int. J. Cancer 2009, 125, 565-576.

24. Fitzpatrick, L.R.; Wang, J.; Le, T. Caffeic acid phenethyl ester, an inhibitor of nuclear factor-kappaB, attenuates bacterial peptidoglycan polysaccharide-induced colitis in rats. J. Pharmacol Exp. Ther. 2001, 299, 915-920.

25. Circu, M.L.; Aw, T.Y. Reactive oxygen species, cellular redox systems, and apoptosis. Free Radic. Biol. Med. 2010, 48, 749-762.

26. Simon, H.U.; Haj-Yehia, A.; Levi-Schaffer, F. Role of reactive oxygen species (ros) in apoptosis induction. Apoptosis 2000, 5, 415-418. 
27. Lin, W.L.; Liang, W.H.; Lee, Y.J.; Chuang, S.K.; Tseng, T.H. Antitumor progression potential of caffeic acid phenethyl ester involving p75(NTR) in c6 glioma cells. Chem. Biol. Interact. 2010, 188, 607-615.

28. Hengartner, M.O. The biochemistry of apoptosis. Nature 2000, 407, 770-776.

29. Chen, H.C.; Chen, J.H.; Chang, C.; Shieh, C.J. Optimization of ultrasound-accelerated synthesis of enzymatic caffeic acid phenethyl ester by response surface methodology. Ultrason. Sonochem. 2011, 18, 455-459.

30. Wang, L.C.; Chu, K.H.; Liang, Y.C.; Lin, Y.L.; Chiang, B.L. Caffeic acid phenethyl ester inhibits nuclear factor-kappab and protein kinase $\mathrm{b}$ signalling pathways and induces caspase-3 expression in primary human CD4+ T cells. Clin. Exp. Immunol. 2010, 160, 223-232.

31. Orban, Z.; Mitsiades, N.; Burke, T.R., Jr.; Tsokos, M.; Chrousos, G.P. Caffeic acid phenethyl ester induces leukocyte apoptosis, modulates nuclear factor-kappa B and suppresses acute inflammation. Neuroimmunomodulation 2000, 7, 99-105.

32. Xiang, D.; Wang, D.; He, Y.; Xie, J.; Zhong, Z.; Li, Z. Caffeic acid phenethyl ester induces growth arrest and apoptosis of colon cancer cells via the beta-catenin/T-cell factor signaling. Anticancer Drugs 2006, 17, 753-762.

33. Lee, Y.; Shin, D.H.; Kim, J.H.; Hong, S.; Choi, D.; Kim, Y.J.; Kwak, M.K.; Jung, Y. Caffeic acid phenethyl ester-mediated NRF2 activation and ikappab kinase inhibition are involved in NFkappaB inhibitory effect: Structural analysis for nfkappab inhibition. Eur J. Pharmacol. 2010, 643, 21-28.

34. Lee, Y.J.; Kuo, H.C.; Chu, C.Y.; Wang, C.J.; Lin, W.C.; Tseng, T.H. Involvement of tumor suppressor protein p53 and p38 mapk in caffeic acid phenethyl ester-induced apoptosis of c6 glioma cells. Biochem. Pharmacol. 2003, 66, 2281-2289.

35. Junk, D.J.; Vrba, L.; Watts, G.S.; Oshiro, M.M.; Martinez, J.D.; Futscher, B.W. Different mutant/wild-type p53 combinations cause a spectrum of increased invasive potential in nonmalignant immortalized human mammary epithelial cells. Neoplasia 2008, 10, 450-461.

36. Liu, S.Y.; Chiang, M.F.; Chen, Y.J. Role of WW domain proteins WWOX in development, prognosis, and treatment response of glioma. Exp. Biol Med. 2015, 240, 315-323.

37. Steller, H. Mechanisms and genes of cellular suicide. Science 1995, 267, 1445-1449.

38. Nagata, S.; Golstein, P. The fas death factor. Science 1995, 267, 1449-1456.

39. Locksley, R.M.; Killeen, N.; Lenardo, M.J. The TNF and TNF receptor superfamilies: Integrating mammalian biology. Cell 2001, 104, 487-501.

40. Ashkenazi, A.; Dixit, V.M. Apoptosis control by death and decoy receptors. Curr. Opin. Cell. Biol. 1999, 11, 255-260.

41. Rubio-Moscardo, F.; Blesa, D.; Mestre, C.; Siebert, R.; Balasas, T.; Benito, A.; Rosenwald, A.; Climent, J.; Martinez, J.I.; Schilhabel, M.; et al. Characterization of 8p21.3 chromosomal deletions in B-cell lymphoma: Trail-R1 and trail-R2 as candidate dosage-dependent tumor suppressor genes. Blood 2005, 106, 3214-3222.

42. Ashkenazi, A.; Holland, P.; Eckhardt, S.G. Ligand-based targeting of apoptosis in cancer: The potential of recombinant human apoptosis ligand 2/tumor necrosis factor-related apoptosis-inducing ligand (rhapo21/trail). J. Clin. Oncol. 2008, 26, 3621-3630.

43. Elmore, S. Apoptosis: A review of programmed cell death. Toxicol. Pathol. 2007, 35, 495-516.

44. Perkins, N.D. The REL/Nf-kappa B family: Friend and foe. Trends Biochem. Sci. 2000, 25, 434-440. 
45. Green, D.R.; Reed, J.C. Mitochondria and apoptosis. Science 1998, 281, 1309-1312.

46. Grémy, O.; Benderitter, M.; Linard, C. Caffeic acid phenethyl ester modifies the TH1/TH2 balance in ileal mucosa after gamma-irradiation in the rat by modulating the cytokine pattern. World J. Gastroenterol. 2006, 12, 4996-5004.

47. Kim, E.Y.; Ryu, J.H.; Kim, A.K. Cape promotes trail-induced apoptosis through the upregulation of trail receptors via activation of $\mathrm{p} 38$ and suppression of JNK in SK-HEP1 hepatocellular carcinoma cells. Int. J. Oncol. 2013, 43, 1291-1300.

48. Chiao, C.; Carothers, A.M.; Grunberger, D.; Solomon, G.; Preston, G.A.; Barrett, J.C. Apoptosis and altered redox state induced by caffeic acid phenethyl ester (cape) in transformed rat fibroblast cells. Cancer Res. 1995, 55, 3576-3583.

49. Chen, Y.J.; Shiao, M.S.; Hsu, M.L.; Tsai, T.H.; Wang, S.Y. Effect of caffeic acid phenethyl ester, an antioxidant from propolis, on inducing apoptosis in human leukemic HL-60 cells. J. Agric. Food Chem. 2001, 49, 5615-5619.

50. Gocmez, C.; Celik, F.; Kamasak, K.; Kaplan, M.; Uzar, E.; Arikanoglu, A.; Evliyaoglu, O. Effects of intrathecal caffeic acid phenethyl ester and methylprednisolone on oxidant/antioxidant status in traumatic spinal cord injuries. J. Neurol. Surg. A Cent. Eur. Neurosurg. 2014, 76, 20-24.

51. Choi, K.; Han, Y.H.; Choi, C. $N$-acetyl cysteine and caffeic acid phenethyl ester sensitize astrocytoma cells to FAS-mediated cell death in a redox-dependent manner. Cancer Lett 2007, 257, 79-86.

52. Sanderson, J.T.; Clabault, H.; Patton, C.; Lassalle-Claux, G.; Jean-François, J.; Paré, A.F.; Hébert, M.J.G.; Surette, M.E.; Touaibia, M. Antiproliferative, antiandrogenic and cytotoxic effects of novel caffeic acid derivatives in lncap human androgen-dependent prostate cancer cells. Bioorg. Med. Chem. 2013, 21, 7182-7193.

53. Cormier, K.; Harquail, J.; Ouellette, R.J.; Tessier, P.A.; Guerrette, R.; Robichaud, G.A. Intracellular expression of inflammatory proteins s100a8 and s100a9 leads to epithelial-mesenchymal transition and attenuated aggressivity of breast cancer cells. Anticancer Agents Med. Chem. 2014, 14, 35-45.

54. Benzina, S.; Harquail, J.; Jean, S.; Beauregard, A.P.; Colquhoun, C.D.; Carroll, M.; Bos, A.; Gray, C.A.; Robichaud, G.A. Deoxypodophyllotoxin isolated from juniperus communis induces apoptosis in breast cancer cells. Anticancer Agents Med. Chem. 2014, 15, 79-88.

55. Thomas, M.; Kalita, A.; Labrecque, S.; Pim, D.; Banks, L.; Matlashewski, G. Two polymorphic variants of wild-type p53 differ biochemically and biologically. Mol. Cell. Biol. 1999, 19, 1092-1100.

56. Doiron, J.A.; Metayer, B.; Richard, R.R.; Desjardins, D.; Boudreau, L.H.; Levesque, N.A.; Jean-Francois, J.; Poirier, S.J.; Surette, M.E.; Touaibia, M. Clicked cinnamic/caffeic esters and amides as radical scavengers and 5-lipoxygenase inhibitors. Int. J. Med. Chem. 2014, 2014, 931756-931768.

57. Prior, R.L.; Wu, X.; Schaich, K. Standardized methods for the determination of antioxidant capacity and phenolics in foods and dietary supplements. J. Agric. Food Chem. 2005, 53, 4290-4302.

Sample Availability: Samples of the compounds $\mathbf{2 - 1 8}$ are available from the authors.

(C) 2015 by the authors; licensee MDPI, Basel, Switzerland. This article is an open access article distributed under the terms and conditions of the Creative Commons Attribution license (http://creativecommons.org/licenses/by/4.0/). 